This PDF is a simplified version of the original article published in Internet Archaeology. Enlarged images, and interactive features which support this publication can be found in the original version online. All links also go to the online version.

\title{
Shared Archaeological Heritage: the European Archaeology Days
}

\section{Pascal Ratier}

\section{Summary}

A discipline where several scientific fields meet, archaeology studies the material traces of civilisations, from prehistory to the contemporary era. By enriching our knowledge of the societies that came before us, it contributes to a better understanding of today's world and helps sharpen citizens' critical outlook. When it comes to protection, conservation, awareness-raising and education, archaeological heritage is a significant societal opportunity for Europe. At a time marked by concerns over identity and community, archaeology is a source of openness and tolerance. The European Archaeology Days can therefore help shape a common identity, while preserving the cultural diversity that characterises a Europe of multiplicity. Developing this initiative could encourage open access to culture for all and, among future generations, foster acceptance of the 'Other' in all their differences. In this context, it feels important to give the event a European dimension.

\section{National Archaeology Days in France, a landmark in the cultural landscape!}

In 2010, the French National Institute for Preventive Archaeological Research (INRAP) introduced a nationwide event to present the full extent of archaeological activities, 'from dig to museum', one Saturday in June. The aim was to maximise public awareness of archaeological heritage and research by seeking to open up these activities to a 'novice' audience unaccustomed to visiting archaeology sites and venues. The full panel of stakeholders in archaeology gets involved in these Archaeology Days, with the aim of introducing visitors to the treasures that make up their national heritage and the secrets of the archaeological professions. Archaeological excavators, research organisations, universities, museums and archaeological sites, laboratories, associations, archives and 
local authorities are all encouraged to organise innovative, creative and interactive activities for the general public.

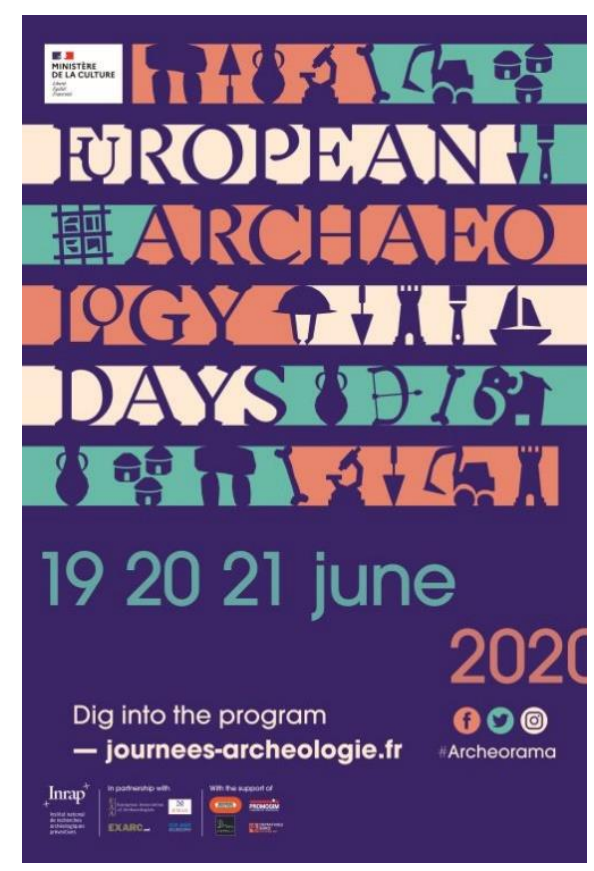

Figure 1: The poster for the European Archaeology Days 2020 @Inrap

We have defined three main objectives for the event: showcasing the entire archaeology process to the public; engaging professionals and institutions operating in the field of archaeology; involving new audiences unused to visiting archaeology sites.

In 2010, around a hundred organisers put on a range of activities for the public one Saturday in June. This first event of its kind was a notable success and led to a repeat of the operation over two days in June, the full weekend over the following years, then extended to three days, adding the Friday to target schoolchildren in particular (see Figure 2), all under the aegis of the French Ministry of Culture.

Since the first year, the event has continued to grow, both in terms of the number of structures involved and the visitors received. In 2018, more than 570 organisations took part in the ninth year of the event across France, welcoming over 200,000 visitors. The event also generated more than 2000 media mentions, the vast majority of which come from the daily regional press. A dedicated website, journees-archeologie.fr, allows organisers to register and share their programme with potential visitors, who can thus organise their days out using the geolocation function. The website plays a key role in communication and received over 150,000 visitors in the two months prior to the event. It is also worth noting that the National Archaeological Days are a local event, with three out of four visitors coming from within a radius of $20 \mathrm{~km}$. 


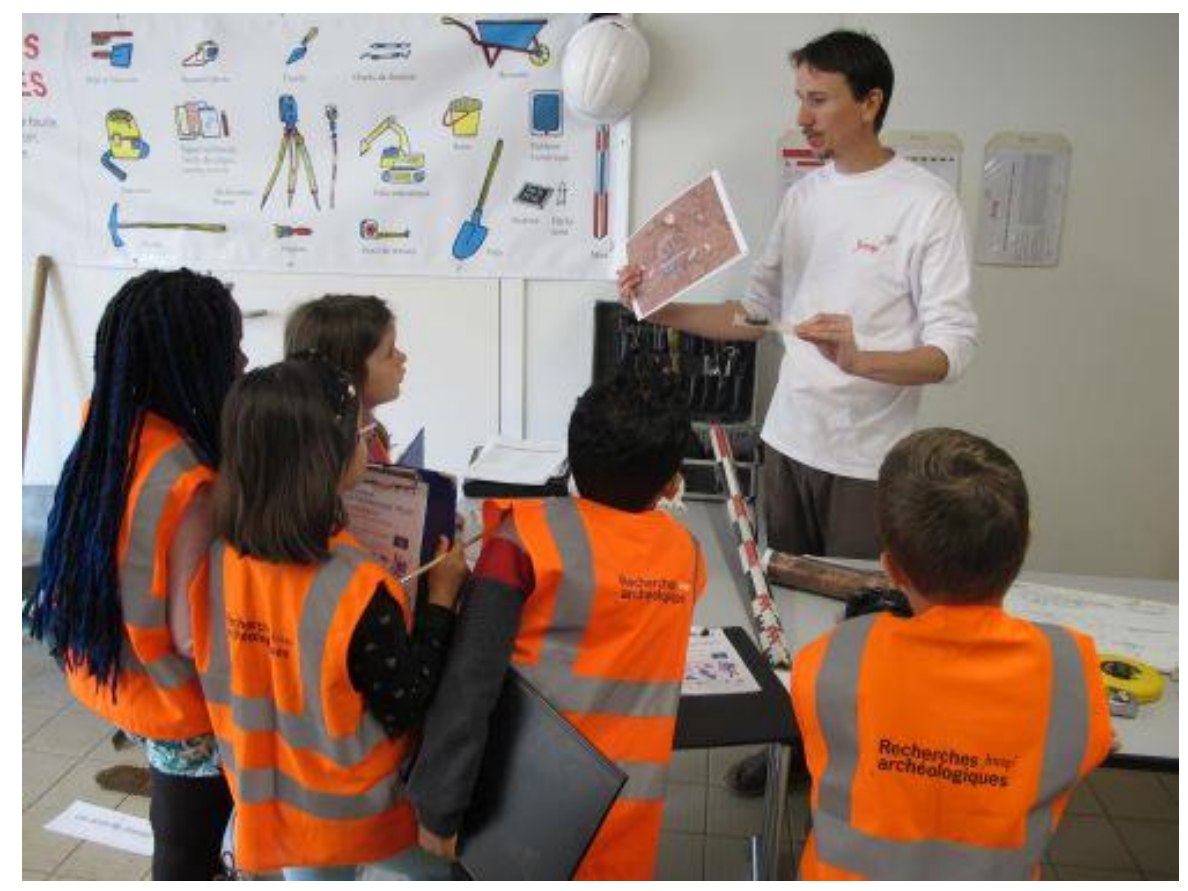

Figure 2: A workshop for schoolchildren in Bègles (France) @Auregane Binard, Inrap

\section{2019: A First European Edition}

The outcome of the French event has been highly positive and demonstrates the public's thirst for knowledge while proving that the National Archaeology Days fulfil an expectation felt among the people involved in archaeology.

In 2019, for the tenth anniversary of the National Days, the event was extended to Europe, with 18 countries and 1160 locations involved, including 14 UNESCO World Heritage Sites. The organisers of the European Archaeology Days put on an array of activities to demonstrate 'archaeology in the making' (see Figure 3) and help European citizens get to know and question their past. Interest in archaeology goes beyond the French borders and, according to a survey coordinated by INRAP (Nearch/Harris Interactive project), $90 \%$ of Europeans consider archaeology useful, while $85 \%$ would like to visit archaeological sites.

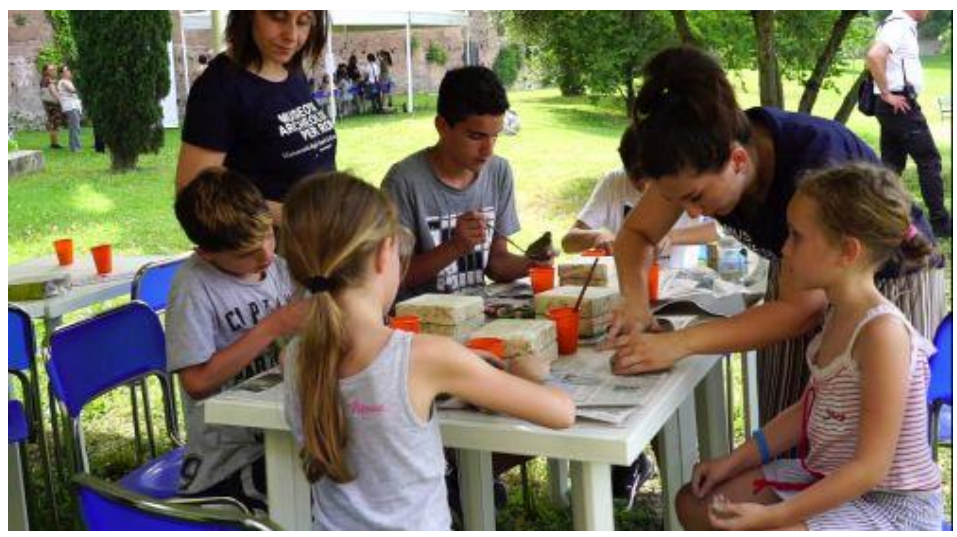

Figure 3: Fresco and ceramics on the Barberini Vineyard @Colosseum Archaeological Park (Italy) 
With the COVID-19 pandemic, it was not possible to hold the 11th Archaeology Days in their usual format. However, under the aegis of the French Ministry of Culture, INRAP launched the \#Archeorama event to continue to celebrate archaeology with the public. In addition to in-person events where the health situation permitted, \#Archeorama enabled digital events while showcasing online resources. There were, for example, live meetings of archaeologists on social media, the release of unpublished videos, live conferences, virtual tours of exhibitions, and 3D models of archaeological objects and sites.

With nearly 1000 in-person or exclusively online initiatives, the 2020 European Archaeology Days and \#Archeorama were a great success. In total, we counted more than 180,000 visits to the website, with 15,000 single visitors during the three-day event (see Figure 4).

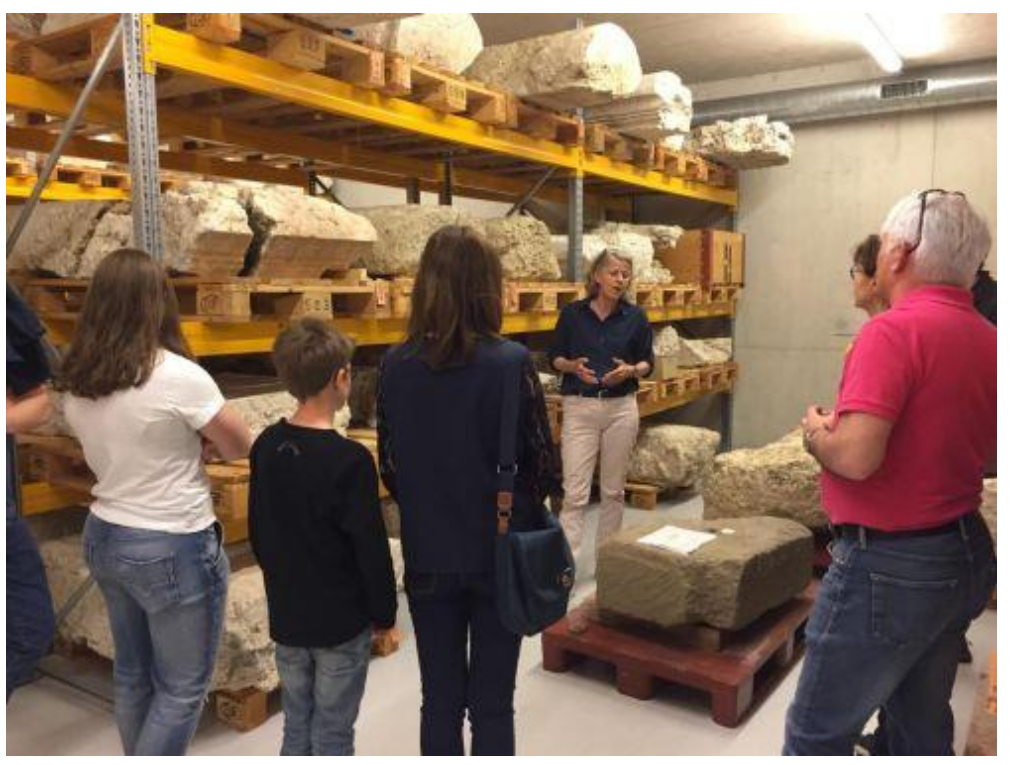

Figure 4: Visit of the archaeological repository of the Museum of Nyon, (Switzerland) CMuseum of Nyon

The European dynamic has continued, with 28 member countries of the Council of Europe taking part in 2020, and nearly 500 different European organisers.

\section{Archaeology Villages, Archaeology in Public Space}

Since 2010, the Archaeology Days have been centred around two main components: the Archaeology Villages and the notion of 'Archaeology in the making'.

The Archaeology Villages have been deployed for several years now; they bring together a region's full array of stakeholders at a single site, and thus involve museums, archaeology research teams, archives, libraries, associations, universities, and so on. The idea is to set up at a public, city-centre location to connect with local residents and reach out to a new audience not necessarily interested in archaeology at the outset (see Figure 5). In fact, in the first few years of the National Archaeology Days, events were 
mainly held in rural areas and the large populations in the big urban areas were unable to find activities in their vicinity.

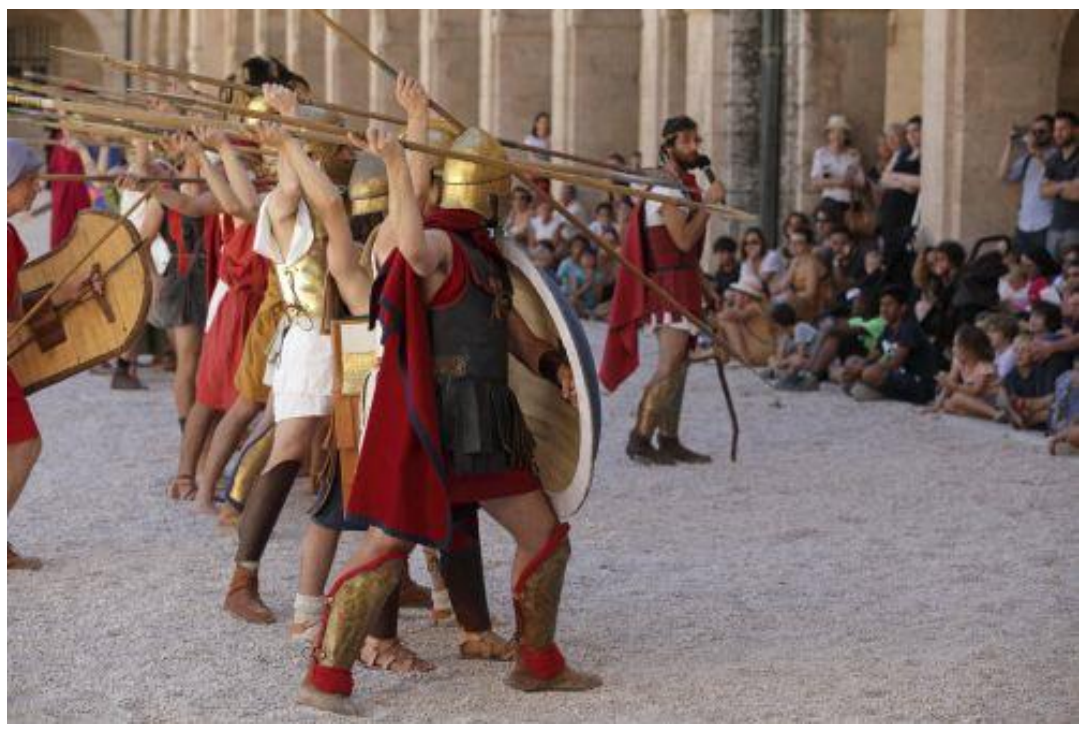

Figure 5: Reconstruction of a Greek camp at the Archaeology Village of Marseille, (France) (CRemi Benali, Inrap

In 2019, ten Villages were set up across France to increase the awareness of a broad audience: they now account for $20 \%$ of total visitor numbers during National Archaeological Days.

\section{An Objective for the European Archaeology Days: 'Archaeology in the making!'}

Science is a social process that has always been driven by debates and controversies, from which a consensus eventually and temporarily emerges within the scientific community, all against a specific cultural and political background. The desire to interact with the public is therefore incredibly important: it is crucial to listen to citizens' perspectives and their questions by enabling direct links with scientists, thus giving them the chance to experiment and manipulate.

Archaeology is a discipline that is part of a mission to encourage better knowledge and preservation of heritage. It is interdisciplinary, concerning both the human and 'hard' sciences, and depends on practice in the field. So, how do we reach out to as many people as possible with 'archaeology in the making'? The opening of excavation sites is an important part of the European Archaeological Days (Figure 6). 


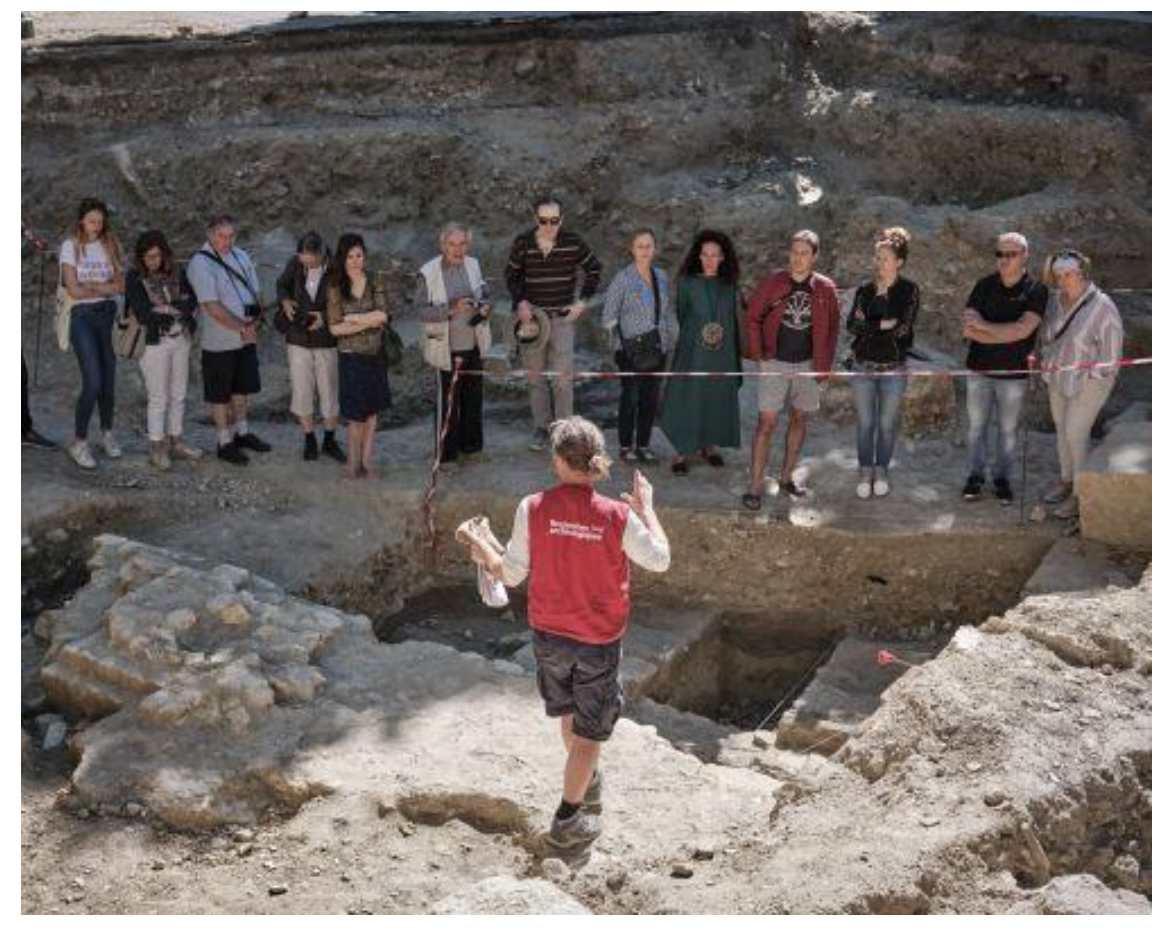

Figure 6: Open day for an excavation site in Narbonne, (France) @Myr Muratet, Inrap

In 2019, 32 Open Days were held at excavation sites in France during the European Archaeology Days, most of which involved preventive archaeology. This type of event can attract a large audience of around 1000 people in one day. The reasons for this success are: public interest in the discipline; local factors: this is 'our history'; the fact that excavation sites are not usually open to the public.

A preventive excavation site is not normally accessible to the public, so significant preparatory work is required in terms of logistics, site safety, accessibility and communication. Opening dig sites and research centres to the public present significant challenges for implementation. It is also a means of doing away with the clichés surrounding archaeology and showing what the profession is really about. Being accessible is key, which means meetings with professionals.

It is also important that the moment remains 'exceptional', giving visitors a glimpse of what goes on behind the scenes at a heritage site, something that non-professionals don't usually get to see. This increases the appeal and the value of the moment. The various surveys we have carried out among visitors show that opening excavation sites draws a new set of visitors who had never been to an archaeological site or museum before. Of course, this is precisely one of the main objectives of the European Archaeology Days: attracting new audiences to archaeology.

Museums are also a suitable venue for presenting 'archaeology in the making' (see Figure 7). They can be transformed into 'archaeological laboratories' at no additional cost. They already bring together researchers and experts working in the field and are able to exhibit the entire archaeological process. 


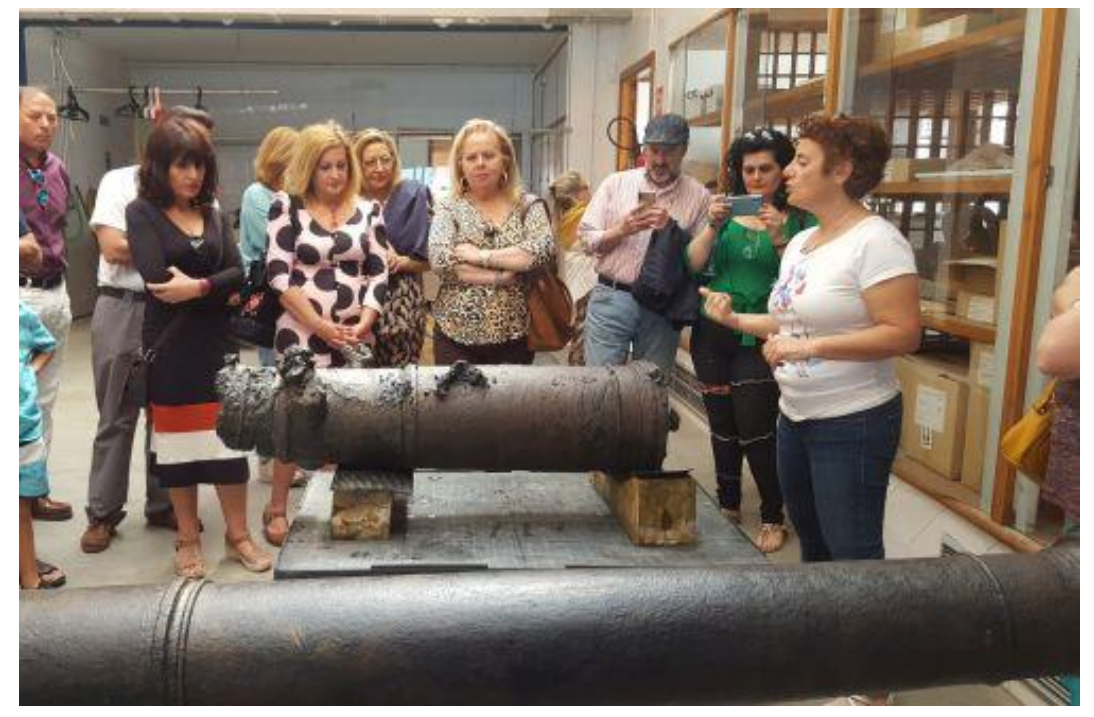

Figure 7: Open day for the Underwater Archaeology Centre of Cadiz, (Spain) (C)Andalusian Regional Government

On a site, it is impossible to let people take part in the excavation. However, with the archaeologists' help, this activity can be reproduced in a museum (see Figure 8). In addition, museums bring together researchers and give them a chance to talk to the public, re-creating laboratory conditions and enabling close contact. In addition, museums can open the areas where archaeological objects are stored, offering small group visits.

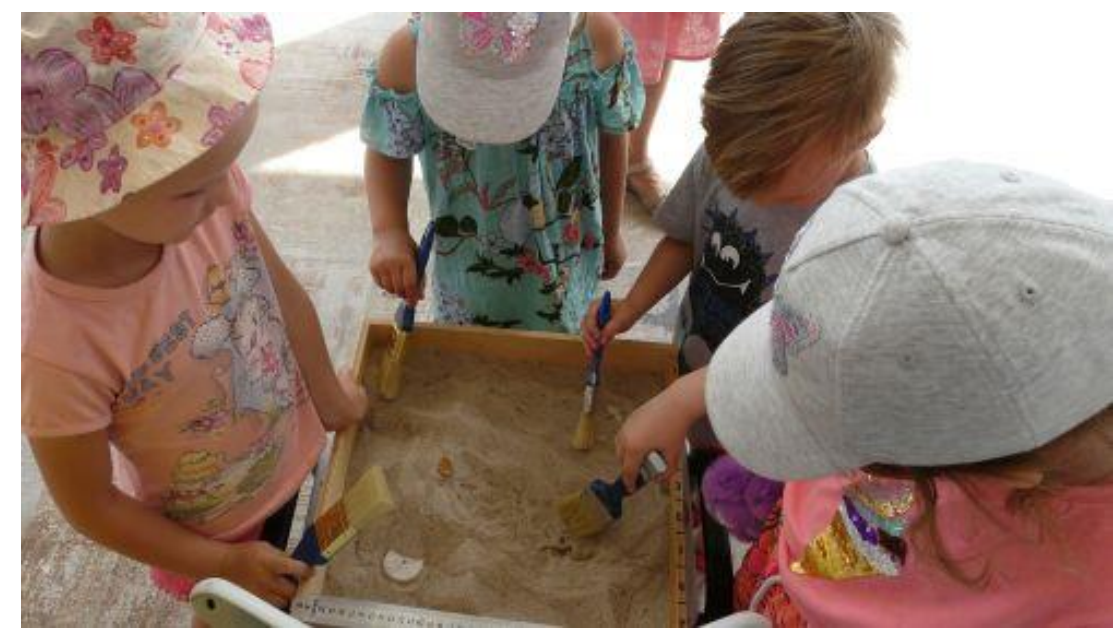

Figure 8: Excavation simulation workshop at the National Museum of Lithuania CNational Museum of Lithuania

Museums are an ideal place for 'archaeology in the making', although of course, going out into the field remains particularly important. In museums, communication is the task of cultural mediators and experts, while archaeologists do not necessarily have the opportunity to speak to the public. Focus on the field, either at an excavation site or in a laboratory, makes it possible to forge links with visitors who are always keen to meet archaeologists and professionals. 


\section{How can we Develop the European Archaeology Days?}

In France, INRAP plays a coordinating role and provides its services to organisers, including as a website (journees-archeologie.fr), downloadable communication materials and media partnerships to promote the event as widely as possible. Another of the Institute's tasks is to mobilise stakeholders from across the region, 'from dig to museum'.

The event has only been able to reach its audience thanks to national communication efforts headed by INRAP, a national organisation, backed by work from the event organisers via their usual networks. The organisation chosen by France is linked to the French model of heritage protection: national centralisation, local variations. This is not a model to be duplicated, but an example that corresponds to the way the French administration operates.

Depending on the legislation and territorial organisations of each of the countries participating in the European Archaeology Days, other forms of organisation of these days will be put in place. It is therefore important that the public and national authorities in charge of archaeology in the European countries are able to coordinate the event in their countries and include it in their overall policy of promoting archaeological heritage.

We therefore need to set up a network of national correspondents in each country, who will be responsible for mobilising stakeholders and providing communication about the event. In 2020, twelve countries took part in the organisation of European Archaeology Days (see Figure 9).

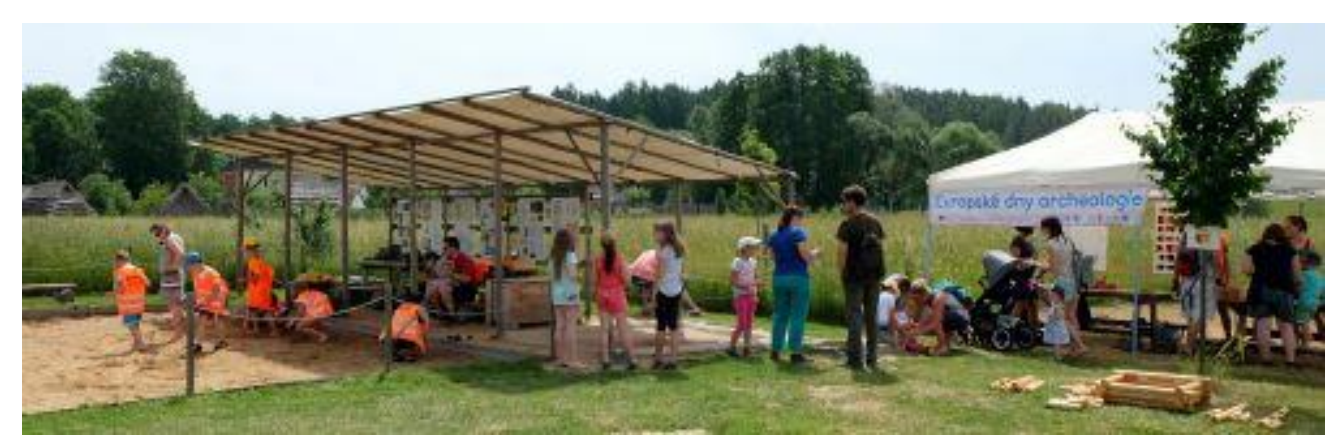

Figure 9: Excavation simulation workshop at the Zemeraj Nature Adventure Park (Czech Republic) (CZemeraj Nature Adventure Park

Finally, what is the context for development of the European Archaeology Days? The most appropriate framework is the Malta Convention, adopted on 16 January 1992 in Valletta within the framework of the Council of Europe (Council of Europe 1992). This convention, which provides the legal basis for the core principles to be applied by national policies designed to protect archaeological objects, advocates (Article 9) a policy of 'promotion of public awareness' which is defined further:

Each Party undertakes: 
- to conduct educational actions with a view to rousing and developing an awareness in public opinion of the value of the archaeological heritage for understanding the past and of the threats to this heritage

- to promote public access to important elements of its archaeological heritage, especially sites, and encourage the display to the public of suitable selections of archaeological objects

This 'public awareness' policy seems to be the most appropriate framework to make these European Archaeology Days shine.

\section{Bibliography}

Council of Europe 1992 European Convention on the Protection of the Archaeological Heritage (Revised), Valletta, 16 January 1992. Council of Europe Treaty Series 143. https://www.coe.int/en/web/conventions/full-list//conventions/rms/090000168007bd25 